\title{
Bulge Testing for Strength Metrics of Detector X-Ray Windows
}

\author{
Joseph Rowley ${ }^{1}$, Kendall Berry ${ }^{1}$, Robert Davis ${ }^{1}$, Richard R. Vanfleet ${ }^{1}$, Sterling Cornaby ${ }^{2}$, Mallorie \\ Harker $^{2}$, Richard Creighton ${ }^{2}$ \\ 1. Brigham Young University, Dept. of Physics and Astronomy, Provo, USA \\ 2. Moxtek Inc., Orem, USA
}

Bulge testing is a technique to measure thin film mechanical properties. First used by Beams[1] to test the strength of silver and gold foils, it has since been improved upon to more accurately model films by comparison with Finite Element Analysis(FEA)[2], and utilize different geometries to measure additional properties[3]. Elastic behavior can be studied, as well as plastic deformations[4]. The basic idea is applying pressure to one side of a film, then measuring the pressure and displacement. The resulting pressure vs. displacement data is then fitted to a cubic function, the coefficients of which will determine a materials Young's modulus and Poisson's ratio.

X-Ray windows are thin solid films designed to withstand a pressure differential while remaining leak tight. Bulge testing is an excellent way to directly test windows mechanical properties. These results are of great benefit to $\mathrm{x}$-ray window as well as $\mathrm{x}$-ray detector design. For example, knowing the maximum deflection of a film under different pressures will let a detector be placed as close to a film as possible while maintaining the integrity of the detector.

There are two basic x-ray windows designs. The first is a single suspended beryllium metal film, sometimes with an additional corrosion resistant protective coating. The other is a stack of thin films, incorporating a polymer film, on top of a support grid. The first type of film is well described by the bulge equation, while the other is not. However, testing can be done directly on the stack of thin films to determine strength of the film without the support structure. The information generated can aid in the design and assist a FEA model's accuracy.

Fig. 1 is a schematic of the setup used for bulge testing. A Keyence LK-G5001P controller and LK-H052 laser displacement sensor are used to measure the displacement of the bulging film. A Newport 426 stage and Newport Newstep NSA12 are used to position and scan the sensor over the film. An electronic pressure regulator along with a pressure transducer control and measure the pressure applied to the film. An MFC measures the flow of air to the film. The laser displacement sensor is based on diffuse reflections. If a sample is too transparent, or has a mirror surface, the sensor does not operate. In these cases colloidal silver is applied to the sample, allowing diffuse reflections without altering the film and keeping the film displacement relatively unchanged. The ability to measure transparent and reflective films is very important for the success of this work.

Fig. 2 is a graph of the bulge across the diameter of a circular film. This candidate window was $3.5 \mathrm{~mm}$ in diameter. From this graph it can be seen that the displaced film has a circular cross section. From several scans of the radius and different pressures, the strength of the film can be obtained

Fig. 3 is a table displaying the displacement data at the center of the Moxtek's AP 5 small window at 1 atm. 


\section{References:}

[1] J. W. Beams, "Mechanical Properties of Thin Films of Gold and Silver" (1959), p. 183

[2] Martha K. Small and W.D. Nix, Journal of Materials Research, 7 (1992), pp. 1553-1563.

[3] J.J. Vlassak and W.D. Nix Journal of Materials Research, 7 (1992), pp 3242-3249.

[4] Y. Xiang, X. Chen and J.J. Vlassak, Journal of Materials Research 20 (2005), pp 2360-2370.

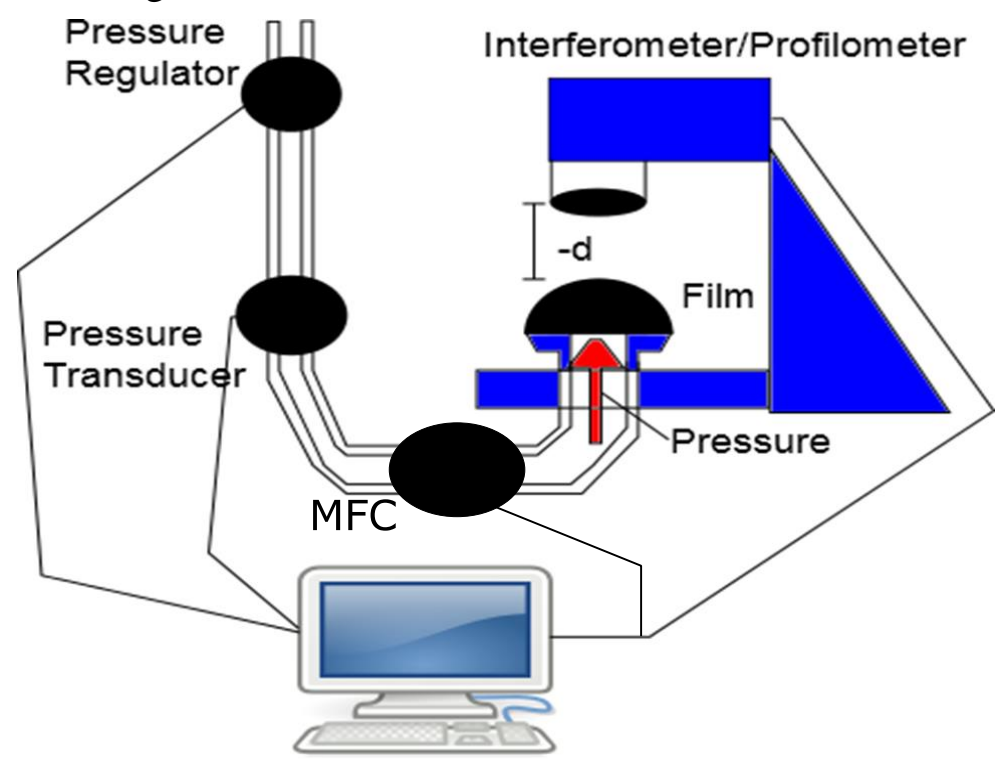

Figure 1. Schematic of Bulge Test Setup

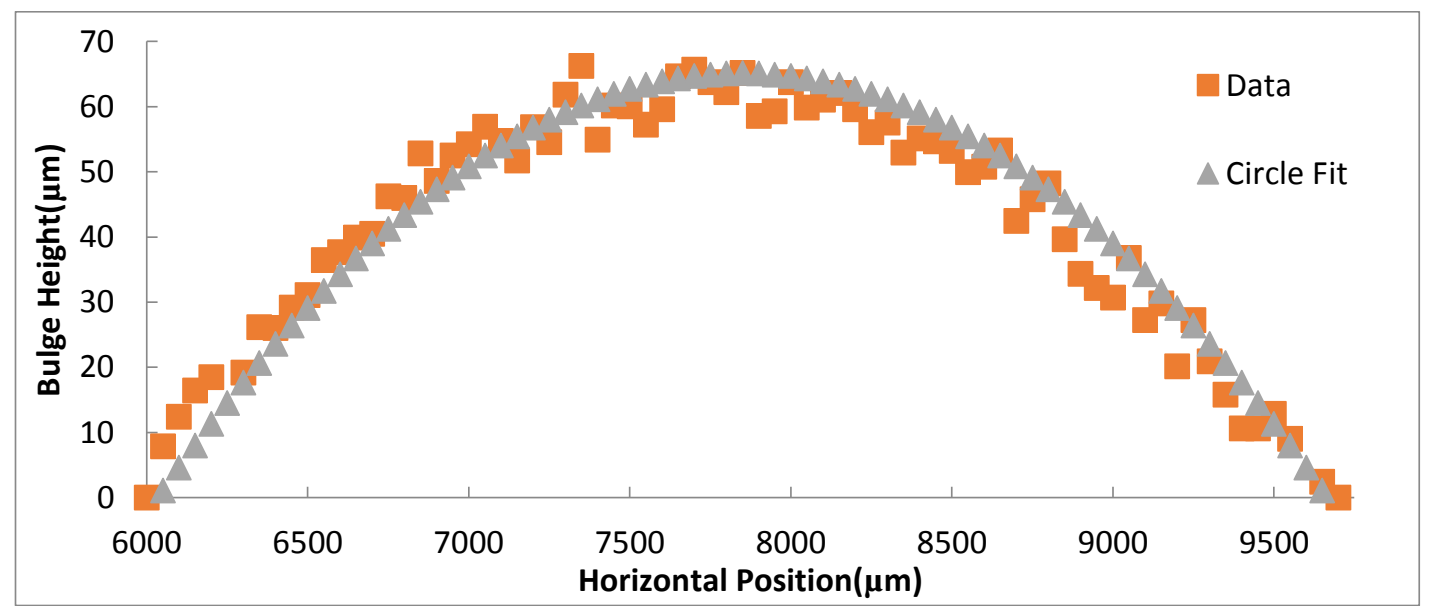

Figure 2. Bulge of X-ray window. Height of the bulge along the diameter of the film.

\begin{tabular}{|l|l|l|}
\hline $\begin{array}{l}\text { AP5 small cycle } \\
\text { number }\end{array}$ & $\begin{array}{l}\text { Displacement at 0 atm } \\
\text { in micrometers }\end{array}$ & $\begin{array}{l}\text { Displacement at 1 atm } \\
\text { in micrometers }\end{array}$ \\
\hline Cycle 1 & 0 & 71.885 \\
\hline Cycle 2 & .187 & 71.914 \\
\hline Cycle 3 & -.059 & 71.884 \\
\hline
\end{tabular}

Figure 3. Table of Moxtek's AP5 small displacements at 1 atm 